\title{
Reading against the Digital Archive: Historiography and What Is Not
}

\author{
Amy Young1*, Joshua Gunn², Jon Hoffman³, Barry Brummett ${ }^{2}$ \\ ${ }^{1}$ Department of Communication and Theatre, Pacific Lutheran University, Tacoma, USA \\ ${ }^{2}$ University of Texas at Austin, Austin, USA \\ ${ }^{3}$ Department of Communication, University of Maryland, College Park, USA \\ Email: youngam@plu.edu, slewfoot@mail.utexas.edu, ibhoffman@gmail.com, brummett@austin.utexas.edu
}

Received 18 March 2015; accepted 2 April 2015; published 7 April 2015

Copyright (C) 2015 by authors and OALib.

This work is licensed under the Creative Commons Attribution International License (CC BY). http://creativecommons.org/licenses/by/4.0/

(C) $\underset{\mathrm{EY}}{\mathrm{B}}$ Open Access

\begin{abstract}
Social media sites like Buzzfeed and Twitter provide significant opportunities for understanding circulation of meaning in our contemporary media ecology. Aligning these social and viral media with cultural productions and reproductions, we argue that Heidegger's theoretical frame of historiography illuminates the ways in which genres are created, memed and mutated across the digital archive. A homological historiography, then, highlights social and viral media as those that require constant feeding, expanding the digital archive and calling upon scholars and lay audiences to consider the limits of the form.
\end{abstract}

\section{Keywords}

Homology, Buzzfeed, Twitter, Historiography, Digital Archive

Subject Areas: Journalism and Communication

\section{Introduction}

In this essay, we freak — or post-unqueer - the archive by reading against the DeLorian tendency to mystify matter, and to mystify what matters — often by confusing temporalities of past and future [1] [2]. A moribund logic of pure transcendence can take us far in this pursuit, but only so far and only as an ideal, for if we go too far we will lose the reader the Bigger Bang (that is, to not being able to read at all). Before accelerating to the limit condition whereby a paradigm reader might collapse, somewhat fortunately, a bit of recalcitrance of dogma arrives to halt the dropping, bringing the postcolonial implications of the archive into the rough relief of life and, thereby, in turn leading to what Heidegger dubbed "the call": beyond the question of being or not-being, there is the question the possibility of historiography itself. How then to escape the counter-freaking that one inevitably

*Corresponding author. 
raises, like a revenant deconstruction, when one undertakes to digitize [3]? How to use the recalcitrance of dogma to halt the parade of death and let the archival human emerge by digital means, but in a way that holds open the question, which is to say, the possibility of some future and unforeseen person to arrive in something and not proclaim to be the new, old "John and Susan Sixpack" of the digital age, Biff or Buzz or Feed or some combination thereof?

Our method to forestall but still allow for a recalcitrance for bearing, or perhaps better said our "intellectual gesture," or another way to express the project, is to say our movement can best be summarized by the phrase "creeping in the murk," which was infamously ascribed to "Sensenbrenner's Ethereal Tortoise" (SET), widely known and discussed in the humanities theoretical. How to capture the object that escapes archiving through its very freakness? How to account for the long reach of global late capitalism through the fancy fern bars of intimidation that have become the Biffeeds and Buzzfeeds of our cultural malaise? Our method will, of course, entail the explicit pushing of the veiny rod of homological critique into the very subject matter that is ever receding on the horizon: the top ten ways of X, or other similar online click-bait. Our conclusions will of necessity, then, become tenuous and in need of confirmation in future research. We write as we sing, always in the key of redemptuous perserveration, if not repetition compulsion.

\section{Literature Review}

In her seminal and rhetorically inseminating essay on genre, Carolyn Miller argues that genre is useful "not because it might permit the creation of some kind of taxonomy, but because it emphasizes some social and historical aspects of rhetoric that other perspectives do not” [4]. Said differently, we long to classify but ought only satisfy that urge in order to situate action-in this case, the freaking-of-the-freak that characterizes the Chicky-Ba Bullet List like those on Buzzfeed. What fuses the freakishness together, in this case? Bifffeeds and Buzzfeeds are often congically bound, exposing rhetorics of sex, sexuality, and physical relations as an engine of this kind of cultural congress. That is, lists often rely on vivid and borderline pornographic imagery of food, barelyclothed young men and women, or the combination of food and scantily clad people to attract attention and keep the eye and hand(s) moving from list to list. While food porn suggests imminent freaking, the visually arresting nature of the imagery keeps attention on the list and suggests that the freak will, in turn, be freaked.

The Leak, then, is a rich rhetorical text because it is grounded in action and rhetoric scholars are as guilty as any of ignoring that thrust of scholarship in our unwavering focus on the oral [5]. Genre, according to Miller, Burke, Bitzer and others, also expose the exigencies that compel them. Bitzer describes these exigencies as a "complex of persons, events, objects, and relations" [6] and Burke uses the terms "motive" and "situation" [7] to get at the sense of urgency implicit in The Leak. Indeed, even Aristotle described The Leak in his treatment of epideictic rhetoric — a bringing together of opportunity and action. In other words, these exigencies "reflect the rhetorical experience of people who create and interpret the discourse" [8]. So what might we glean about motive from those that create these lists? Or more pertinently, how might we interpret the union of motive and situation created by these lists?

Moving from theory into analysis, the BuzzFeed list "52 Hilarious \#ActivistPickUpLines for Valentine’s Day" provides a useful text for scholars to explore the role of exigence in genre and in the broader sociopolitical sphere. Pick up lines include gems like, “I'd invite you over to my place, but I don't believe in private property” and "I'm a socialist in the streets and an anarchist in the sheets." While other critics might dismiss these lines as frivolous or superficial, we argue they situate this list in a broader pubic sphere [9], a recognition of gendered and feminist renderings of political activism. In the midst of the kind of anti-intellectual drivel that accompanies the fourth wave, this BuzzFeed list accomplishes a satirical critique of the hegemonic perspective on protest. That is, protest is necessary as part of political struggle, but protest also threatens the ordered teleos of the public/pubic divide. Exigence is, at its center, ideological and marks genre-in this case the genre of the list-as an ideological engine. In other words, exigence is the recognition of the freaking of (a) genre. The Leak, therefore, is the metagenre of digital life.

But genre is not only about exigence, it is also about pattern or trendline or class. Karlyn Kohrs Campbell and Kathleen Hall Jamieson explain that "the critic who classifies a rhetorical artifact as akin to a class of similar artifacts has identified an undercurrent of history rather than comprehended an act isolated in time" [10]. Returning to the BuzzFeed list on \#ActivistPickUpLines, critics should (re)consider the historical conjunction of romance and persuasion. Contributions like, "I'm underrepresented. In your pants" and "Hey baby. I just found out our shirts were manufactured in unfair working conditions; let's take them off” harken to Gorgias' "Encomium 
of Helen" and Plato's "Phaedrus." As Eric S. Jenkins and Josue David Cisneros posit that love is "rhetoric of form of living labor and draw on this notion to forward a radically constitutive ontology" of love [11]. Love, then, is an undercurrent of rhetorical study and scholarship from the earliest days of Western thought and continues to circumscribe our social experiences [12]. The BuzzFeed list, then, is an example that connects not only love and rhetoric, but love with political and social protest. Here, love functions on at least two distinct levels. The first is love of another individual or an individual's body - that is the skin-level meaning. The second is love of a cause that one would bother protesting for-that is the deeper movement and the way that love as a class/pattern/trend in a broader sense. In other words, love's rhetorical power is both a discreet and identifiable snapshot, but that snapshot is integrated into the photographic spectrum or rhetorics of love across time. If we consider how exigence and class intersect, we would also note that love may keep us together on the one hand, and on the other, it may compel very real political change.

\section{Methodology}

A rhetorical analysis, we argue, helps ground our social and viral media texts in a larger sociopolitical milieu. In this section, we examine the Chicky-Ba bullet list as seen regularly on Buzzfeed and a selection of tweets from Pope Francis' Twitter feed in order to understand the ways genre, historiography and homology intersect in a mediated context. To interrogate this rich topos, we ask two interrelated research questions:

RQ1: How do homological structures frame the kinds of rhetorics produced by Buzzfeed lists and Pope Francis' tweets?

RQ2: How can we understand these homological resonances as arbiters of the broader media ecology?

\section{Discussion}

We recognize that proposing the LT as a more contemporary SET like structure poses challenges, if only because of bipedism and the somewhat belated line of flight taken by contemporary goths or punks into emo- and scream-core, which threatens to drown out stragetic liking and status posery with renewed rounds of bisphasic freaking. In other words, encouraging freaks risks accelerating freaking too far, thereby undoing the archive into undulating threads of irrelevance, thereby creating a portal or entrypoint for futurist Bifffeeds and Buzzfeeds. Consequently, we are prepared to specific a specific procedure of Top-Ten listing that both allows for existing and imminent freaking and still in turn freaks-the-freak, so to speak: Chicky-Ba Bullet Lists. The Chicky-Ba Bullet List is a way to provide a generic framework for understand The Leak as hermeneutical entrypoint.

To begin, then: Facebook. What is it to "like" that which is always already within the digital archive Facebook itself is only but one representative? We note from the start the inherent freaknessness of the "status update" and its likedness, from which multiple identities must perforce arise and arise again, for continuous arisal is the preconduction of anything that "feeds": it must always be fed. It is voracious in its appetite, creating sheaves and sheaves of affirmation that ultimately hides, conceals, obscures, or puffs. Consider the effect of such sheaving on intersubjective archiving of thoughts and memories when multiple "likes" follow one upon the other, like turtles all the way down (or up?) until the very limit of one's bornness, signified by the icon of a bald blue infant, is no longer accessible by clicking "About." Anecdotal evidence abounds to support the observation, beyond mere conjecture, that one's bornness, or the happy, everyday event of wrapping salami around a cheese stick, now rest beneath pixalized layer upon digital layer of likednessthat is not only likely today and in the present, but routine, which is to say reverberating and undulating into the future as a sort of ever-present "now." Futurity obscures the "back" for the face until there is no past anymore, irrespective of the claims of DeLorians and theorists of acceleration would claim (even Nick Land, it is said, has retreated into exile) [13]. Of perhaps greatest importance is the panopticonic enforcement of narrow strata of response. One can "like," one can "share," but thus are the limits imposed upon the archive by the very possibility of freaking it. Consider the hegemonic limits of discourse that forbid a cry of "Dislike!” much less "Piffle!” or "Reinvented!” Other possible responses come to mind, all constrained by the dead hand upon the phallus of Facebook—or worse, the Real return of the Kray Twins brandishing virtual Gatlings. No wonder this digital archive reconfigures the incendiary nature of the feudal push into the digital, inviting the re-entry of forgotten (Wikipedia) entries. As presently defunct performance collective Renegade Soundwave once wrote: "The right to deliver/the right to dine/When you sell hardware your time is right/you work with a vengeance/subtract these pleasures/Eye cut/Eye cuts." Needless to say the follow-up of their fog is a refrain that has become all too common: "Chicky-bob b-bob b-bobchicky." 
The refusal of the polysyllabic in response in sentence form instead of song form, be that in updates or the "About," bespeaks a truncation of the affirmation of nuance behind so much phatic utterances, chicky indeed. It becomes apparent then how Facebook is a mirror-which-is-not-a-mirror for those entangled in its skeins. This erasure is very personhood itself, and makes ripe for the reentry of a future persona who poses the danger of surveillance.

This mirroring or two-facedness of Facebook is likewise apparent upon a moment of sober, if unaccustomed, reflection. One must wear earplugs, which forecasts our concluding recommendation. But we note here for the moment, what is reflection but a two-faced presentation of the object and then representation of it through the endless cycling of posts? Note carefully the gesture toward mediation and the global news institutions implied in the very title of "news feed." How Rupert Murdoch can disguise his hand in this feint must be the subject for another essay, but let us note here the unmistakable footprint, like a cat in the grease pot, of institutionalized media structures, now reduced from a great number to a mere four, massive media conglomerates and conglumetes (the rhizomaticmedialets that structure gaps inevitable in mass mediatization, including academic journals). We must then follow the entrainedness of the post and its responses, the likes, the flames, the cries of anguish disguised as repostings with some worry and distance if possible, between the sheaves: What of the ultimate to repost or be thought a recidivist? To put it allegorically (since brokenness or unevenness is the recalcitrant foothold), what is to become, not of all the dogs in kennels, but the memories of dogs in kennels that are archived so? In considering this, note of course the sense of "ruling" in "arch."

What can be more central to the freakiness or the post-unqueering of the digital archive likewise than the possibility, indeed the discursively constrained requirement, of friending and unfriending? For one cannot unfriend that which was not first friended. One can send forth friend requests into the digital night, and post messages explaining the nugatory basis for such inexplicable requests, often from individuals unknown, but one cannot by doing so escape the freakness of that instantiation. In this doubled, reflexive gesture we see an echo of the impending emergence upon the cultural scene of Fifty Shades of Grey, and yet in shades of something paler, or something more pale [14]. Yet let us not assume that these questions arise only in regard to Facebook, for other DeLorian party games await us to oppose, disguised as Instagram, Twitter, or Snapchat, all of which betray the possibilities of The Leak. The Leak, we propose, is our present-day, contemporary iteration of "Sensenbrenner's Ethereal Tortoise" (SET), which of course was made most recently famous by WikiLeaks, but we also venture slowly makes its way as a sister or abiding recalcitrance to impede the never-ending sheaving of digital sedimentation. The Leak, or TL for short, rearrives the SET in a new guise by opposing the acceleration of the "like," the "update," and the "share" with the incessant but creeping and therefore unnoticeable donkey-concept of reliable pad of absorbance. In this way of conceptual tight-cling, the collection of the mark of the human is reserved both conceptually and materially in a SET like structure, forever providing a REAL analog counterpart to digital freaking, in a sense having the benefit of continued identity in light of the fracking frenzy that so plagues the United States. This approach allows us to continue freaking the archive in a postpersonal manner that both continues the freaking already inherent to networking archivealtiy but at the same time redemptively capture the droppings of "real life" that preserve the bornness and live events of everyone participating in the life network.

What bigger Leak-freaking exigency is there than the Pope joining Twitter? Jorge Mario Bergoglio was elected Pope on March 13, 2013 and took the name Francis. His predecessor had joined Twitter only a few months prior using the name @Pontifex (meaning “bridge builder” in Latin) in December 2012 and tweeted 39 times until his resignation on February 28 [15]. The first tweet of the new Pope was on March 17, 2013: "Dear friends, I thank you from my heart and I ask you to continue to pray for me. Pope Francis.” @Pontifex typically tweets every two or three days and has amassed 519 tweets as of February 8, 2015. His tweets range from offering prayers during periods of conflict to calls to faith such as "The Lord is knocking at the door of our hearts. Have we put a sign on the door saying: 'Do not disturb'” [16]? This down-to-earth metaphorical tone is typical of Francis' communication style. Pope Francis currently has 5.54 million followers on twitter and his tweets have a collective total of 3.8 million retweets.

Though Francis' predecessor established the Pope's twitter presence, Francis is truly the first Pope to embrace the Twitter age, or, more broadly, the age of the digital archive. In fact, Twitter could be seen as one of the "existential peripheries" to which he has directed the Church to be present. Yet given the disparities of attention inherent to "celebrity" accounts with millions of followers, how can the virtual presence of @Pontifex actualize The Leak of the Pope's existential exigence? For it is in the excesses that we see The Leak; yet also in the excesses we are farthest from experiencing it. 
For instance, one follower tweeted at the Pope for guidance: “@Pontifex How would you know if you relationship with God is broken? \#askpontifex” asked @Proutschool on November 12, 2014. Unsurprisingly, Pope Francis did not respond. What does this tell us about political change in the age of The Leak? Can a (dis)embodied post-unqueering of the Pope, channeled through his freaked presence of the Twitter archive truly "reach" his followers. And as the Derridean haunting of this particular tweet (r)evokes, can a relationship with a physical being ever be unbroken? And can an archive of that very being's ephemeral referentiality, ironically of course, be the answer?

Perhaps we must look to those most skilled in the art of irony to understand its role in The Leak's political potential. Comedian Rob Delaney (@robdelaney) celebrated the Pope’s arrival on the social networking platform on December 3, 2012 with “.@Pontifex My cousin Sean \& I touched ween heads behind our grandparents' barn when I was 7. Am I going to hell? Welcome to Tweeter!” He also tweeted to Pope Francis: “.@Pontifex Is it okay to masturbation to a small oil painting of my wife when I travel for \#business" [17]? And indeed, does not this question encapsulate the core exigence called forth by the freaking un-queering call of The Leak? I think it tweets for itself [18].

So what has this dematerialized exploration of the modern archive achieve? If we have truly been successful in freaking this political moment, then the above explorations should prove our thesis in the "Triple determination of deductive fidelity" proposed by Badiou. That is, this essay is necessarily dogmatic, yet embodies an "ontological fidelity which is external to ontology itself" [19]. To that end, we have proposed Facebook "likedness", the Buzzfeed list, and the Pope's tweets as entré to The Leak. Embodying The Leak means opposing the acceleration of the "like," the "update," and the "share" with the incessant but creeping and therefore unnoticeable donkey-concept of reliable pad of absorbance [20]. It means deploying "the list" as the metagenre of digital life. Finally, it requires that we embody the existential peripheries of our de-material freaked archival existence, such as the tautological utopian exigence of the Pope "on” Twitter.

\section{Conclusion}

We have argued in this essay that Heidegger's notion of historiography informs the intersection of homology and social media in a way that illuminates cultural vibrations in contemporary media. We found that the ChickyBa bullet lists so popular on sites like Buzzfeed and the tweets Pope Francis regularly sends are generic markers of social, historical, aesthetic, and political engines that can help us better articulate not only the ways in which these media might be used, but also the ways in which they might be used more effectively. Our rhetorical exploration suggests there is an intentionality - a hermeneutic moment that is worth investigating further. To be sure, social and viral media like Buzzfeed and Twitter comprise a terrain of cultural inquiry that deserves more rhetorical attention.

\section{References}

[1] Tierney, S. (2011) Pointless Conversations: Doctor Emmett Brown. Andrews UK, Essex.

[2] Lloyd, C. (2012) What on Earth Happened? The Complete Story of Planet, Life, and People from the Big Bang to the Present Day. Bloomsbury, New York.

[3] Adler, B. (1997) The Uncommon Wisdom of Oprah Winfrey: A Portrait in Her Own Words. Carol Publishing, Secaucus, 3.

[4] Miller, C. (1984) Genre as Social Action. Quarterly Journal of Speech, 70, 151-167. http://dx.doi.org/10.1080/00335638409383686

[5] Richards, I.A. (1936) The Philosophy of Rhetoric. Oxford University Press, London, 109.

[6] Bitzer, L.F. (1968) The Rhetorical Situation. Philosophy \& Rhetoric, 1, 3.

[7] Burke, K. (1950) A Rhetoric of Motives. University of California Press, Berkeley, 99.

[8] Miller, C.R. (1984) Genre as Social Action. Quarterly Journal of Speech, 152.

[9] Young, A.M. and Wright, J.L. (2015) The Anatomy of a Divorce. Women's Studies in Communication, 38, x.

[10] Campbell, K.K. and Jamieson, K.H. (1978) Form and Genre in Rhetorical Criticism: An Introduction. In: Campbell, K.K. and Jamieson, K.H., Eds., Form and Genre: Shaping Rhetorical Action, Speech Communication Association, Falls Church, 26.

[11] Jenkins, E.S. and Cisneros, J.D. (2013) Rhetoric and This Crazy Little "Thing” Called Love. The Review of Communi- 
cation, 13, 85. http://dx.doi.org/10.1080/15358593.2013.797596

[12] McKeon, R. (1987) Rhetoric: Essays in Invention and Discovery. Oxbow Press, Woodbridge, 89.

[13] Land, N. (2012) Fanged Noumena: Collected Writings 1987-2007. In: Mackay, R. and Brassier, R., Eds., Urbanomic, Falmouth.

[14] Brummett, B., Gunn, J., Hoffman, J. and Young, A. (2014) NSFW: Experiencing Immanentism or Transcendence upon Hearing Gilbert Gottfried's Rendition of Fifty Shades of Grey in the Postmodern Workplace, Or Liberatory Criminology. Science Journal of Sociology and Anthropology, 2014, Article ID: sjsa-235.

[15] Pope Benedict’s Tweets Have Been Deleted from the @Pontifex Twitter Account and Archived at the Vatican Website. http://www.news.va/en/twitter_archive

[16] https://twitter.com/Pontifex/statuses/422657625080094720

[17] As of February 11, 2015 This Tweet Had Been Retweeting 258 Times and Favorites 794 Times. It Can Be Located at http://j.mp/askpontifex1

[18] Tetlock, P., Lebow, R. and Parker, G. (2006) Unmaking the West: “What-If?” Scenarios That Rewrite World History. University of Michigan Press, Ann Arbor, 45.

[19] Badiou, A. (2006) Being and Event, Trans Oliver Feltham. Continuum, New York, 252.

[20] Atiyah, M. (2000) 100 Years of Mathematics. Normat, 48, 123-126. 